University of Nebraska - Lincoln

DigitalCommons@University of Nebraska - Lincoln

Publications, Agencies and Staff of the U.S.

Department of Commerce

U.S. Department of Commerce

2007

\title{
Empirical Results Of Salmon Supplementation In The Northeast \\ Pacific: A Preliminary Assessment
}

Robin Waples

NOAA, robin.waples@noaa.gov

Michael Ford

Northwest Fisheries Science Center, mike.ford@noaa.gov

Dietrich Schmitt

Northwest Indian Fisheries Commission, dschmitt@nwifc.org

Follow this and additional works at: https://digitalcommons.unl.edu/usdeptcommercepub

Waples, Robin; Ford, Michael; and Schmitt, Dietrich, "Empirical Results Of Salmon Supplementation In The Northeast Pacific: A Preliminary Assessment" (2007). Publications, Agencies and Staff of the U.S.

Department of Commerce. 452.

https://digitalcommons.unl.edu/usdeptcommercepub/452

This Article is brought to you for free and open access by the U.S. Department of Commerce at DigitalCommons@University of Nebraska - Lincoln. It has been accepted for inclusion in Publications, Agencies and Staff of the U.S. Department of Commerce by an authorized administrator of DigitalCommons@University of Nebraska - Lincoln. 
CHAPTER 21

\title{
EMPIRICAL RESULTS OF SALMON SUPPLEMENTATION IN THE NORTHEAST PACIFIC: A PRELIMINARY ASSESSMENT
}

\author{
ROBIN S. WAPLES, Ph.D. ${ }^{1}$, MICHAEL J. FORD, Pн.D. ${ }^{1}$, \\ AND DIETRICH SCHMITT ${ }^{2}$ \\ ${ }^{1}$ Conservation Biology Division, National Marine Fisheries Service, Northwest Fisheries Science Center, \\ 2725 Montlake Boulevard East, Seattle, Washington 98112, USA (E-mail: robin.waples@noaa.gov) \\ ${ }^{2}$ Northwest Indian Fisheries Commission, 6730 Martin Way, East Olympia, Washington 98516, USA
}

\begin{abstract}
For over a century, aquaculture of Pacific salmon has been used to provide increased harvest opportunities and to mitigate reductions in natural populations due to factors such as habitat destruction, overharvest, and blockage of migratory routes. More recently, attention has focused on the potential of hatchery propagation to reduce risks to and speed recovery of depleted natural populations. A large number of these "supplementation" programs have already been initiated and many more are planned, in spite of the fact that there is almost no empirical information on their long-term effects. Here we present preliminary results of a survey of 22 salmon supplementation programs in northwestern North America. Rather than using a single measure of "success," we evaluated programs according to how well they have accomplished a series of specific objectives. Some major conclusions emerge from the review: (1) many supplementation programs have achieved a measure of success in the aspects of fish culture traditionally associated with salmon hatcheries (e.g., high egg-to-smolt survival; adult-to-adult replacement rates in excess of 1.0); (2) to date, however, little information is available about the performance of hatchery fish and their progeny in the natural environment. Therefore, the premise that hatchery supplementation can provide a net long-term benefit to a natural population is a hypothesis that has not yet been tested. This fact should be kept in mind in evaluating the appropriate use of supplementation programs.
\end{abstract}

Key words: aquaculture, assessment, empirical, hatcheries, environment, Pacific salmon, review, supplementation 


\section{INTRODUCTION}

For over a century, artificial propagation of Pacific salmon (Oncorhynchus spp.), including steelhead (anadromous steelhead trout [O. mykiss]) in the Pacific Northwest has been used primarily to mitigate declines and losses of wild populations. Because the root causes of the declines (e.g., habitat loss and degradation, overharvest, blockage of migratory routes) were too economically, socially, or politically difficult to resolve, hatcheries were used as a substitute for conservation of wild populations (Lichatowich, 1999). More recently, there has been growing recognition that the genetic, ecological, and life-history diversities manifest in wild populations are integral to the long-term sustainability of the resource (National Research Council, 1996). Within the last decade, the listing of many populations of Pacific salmon as threatened or endangered species under the U.S. Endangered Species Act (e.g., Waples, 1995) has required managers to focus on conservation and recovery of natural populations, and this has spurred an increased interest in the use of artificial propagation for conservation purposes-for example, to prevent extinction or speed recovery of a population. Hatchery programs used for these purposes often are referred to as supplementation programs.

The potential conservation benefits of artificial propagation are readily apparent: the raison d'etre of a salmon hatchery is to bypass the high mortality that occurs in early life stages in the wild, and if a hatchery is successful in this regard, it has the potential to produce many times more fish than a wild population can. Although this demographic boost is a necessary component of a successful supplementation program, it is not sufficient by itself to provide a net long-term benefit to wild populations. For the latter to occur it is necessary for the hatchery fish to survive and spawn in the wild and to produce viable progeny that contribute to the natural population. Successful supplementation thus involves the integration of hatchery and natural production, a process that entails significant genetic and ecological risks to the wild population as well as potential benefits (Busack and Currens, 1995).

Evaluating the "success" of supplementation, therefore, requires a comprehensive evaluation of potential benefits and risks, with both being evaluated from the perspective of net long-term effects on wild populations. The last major review of salmon supplementation (Miller et al., 1990) is more than a decade old, and even at the time of completion had some significant limitations. This was illustrated in a recent U.S. Federal Court case involving appropriate use of supplementation of steelhead in Oregon, in which results of the Miller et al. study were cited by both sides. One side quoted the study in support of the contention that most supplementation programs have been successful, while the other side cited the same study to the effect that no supplementation program has been shown to provide a net long-term benefit to a wild population. In fact, both sides were right, as illustrated by the following quote from Miller et al. (1990, p. 4):

"Twenty-five of the 26 supplementation projects we reviewed were considered successful by the principal investigator [emphasis added]. Eighteen of the 
26 projects were quantitatively evaluated. Of the 18,14 are ongoing and four are supplementation evaluation studies. We found no evaluated projects that had rebuilt wild/natural runs to self-sustaining levels."

The explanation for this apparent inconsistency is straightforward. Although the review evaluated the "success" of supplementation, no general definition of success was offered; instead, managers of supplementation programs were asked to evaluate their own programs by whatever criteria they chose to use. Not surprisingly, virtually all programs were judged "successful" in the self-evaluations. In contrast, Miller et al. (1990) found no supplementation programs that could be considered successful if the criterion of success was a self-sustaining natural population.

In this paper we present preliminary analyses from an updated review of supplementation programs for Pacific salmon. Our review attempts to address some of the shortcomings of previous efforts. First, we offer the following definition of supplementation: the intentional demographic integration of hatchery and natural production, with the goal of improving the status of an existing natural population (either in an absolute sense or relative to what its status would be without supplementation). This definition excludes introductions into new habitat or reintroductions into currently barren habitat that formerly supported a native population. Although these are legitimate conservation applications for artificial propagation under appropriate circumstances, such programs present a different set of challenges than does supplementation of an existing population and therefore should be evaluated separately.

Second, instead of using a single, subjective measure of "success," we identify a series of objectives of supplementation programs and suggest quantitative ways of measuring the degree to which the objectives have been achieved. This approach accomplishes several things:

1. It results in a database that allows one to determine which aspects of salmon supplementation are working and which are not.

2. It allows programs to be evaluated directly against their goals, which are not identical across programs (for example, failure to meet a particular criterion might be due to biological or logistic difficulties in executing the program, but it might also occur because meeting that criterion is not one of the program's goals).

3. It highlights uncertainties that should be considered in determining the appropriate use of supplementation.

4. It points to areas critically in need of more research and/or better monitoring and evaluation.

\section{METHODS}

\subsection{Choice of Programs to Include}

For Pacific salmon within their natural ranges, we attempted to obtain information on all programs that met our definition of supplementation. Lists of potential supplementation programs were obtained by soliciting information 
from representatives of state, tribal, and federal agencies that operate hatchery facilities, and by searching through the scientific literature and agency reports. Through this process, we obtained a list of over 250 projects in California, the Pacific Northwest, and Alaska that at least someone thought could be considered "supplementation." Many of these were small, episodic programs for which little or no information was available. After eliminating these programs, we were left with a much smaller list that appeared to meet our definition of supplementation and for which we were able to obtain written reports or other documentation. Finally, to ensure that comparisons and summaries across programs were as meaningful as possible, we included in our analyses only those programs meeting the following criteria:

1. had been in operation long enough and consistently enough to have experienced at least some returns of adults produced in the hatchery;

2. collected broodstock adults from the wild and released juveniles into the wild (that is, we excluded programs that raise captive or wild-caught juveniles to maturity);

3. used broodstock derived principally from a local, native population.

Programs that did not meet one or more of these criteria may meet some definitions of supplementation and may provide benefits to natural populations, but it was not feasible to evaluate them in this study.

In the end, we found 22 projects that met these criteria, and these formed the information base for this review (Table 1).

\subsection{Data Collection and Analysis}

To collect information on the programs, we developed a worksheet consisting of 73 questions. The questions were divided into categories related to information about project administration; the natural population targeted for supplementation; broodstock collection; spawning, rearing, and release methods and results; non-targeted or control populations; and project goals. The questions were designed to elicit the raw data necessary to quantitatively and objectively evaluate the programs, rather than to rely on self-evaluation.

In filling out these worksheets, we first attempted to find the information in papers published in the scientific literature or in agency reports. We sent partially completed worksheets based on this information to the lead agencies operating the supplementation programs for their review. In many cases, the agencies were able to provide additional data. These data were also incorporated into the revised worksheets, which are available from the authors upon request.

Geometric means were used to compute averages across years for survival rates in captivity, adult-to-adult replacement rates, and relative survivals of hatchery and wild fish. Peterman (1981) showed that the geometric mean is more appropriate than the arithmetic mean in studies of stock-recruitment relationships and survival rates because the underlying distributions are typically log-normal rather than normal. 
Table 1. List of supplementation programs considered in evaluating the results of Pacific salmon supplementation programs. Agencies and their contact locations for these programs are provided in Appendix 1. Ag. = agency; Init. = initial; Cur. = current

\begin{tabular}{|c|c|c|c|c|c|c|c|}
\hline \multirow{2}{*}{$\begin{array}{l}\text { Program/ } \\
\text { species }\end{array}$} & \multirow[b]{2}{*}{ Run } & \multirow[b]{2}{*}{ Water body } & \multirow[b]{2}{*}{ Area } & \multirow[b]{2}{*}{ Ag. ${ }^{1}$} & \multirow{2}{*}{$\begin{array}{l}\text { Date of } \\
\text { first release }\end{array}$} & \multicolumn{2}{|c|}{$\begin{array}{l}\text { Principal } \\
\text { goal }^{2}\end{array}$} \\
\hline & & & & & & Init. & Cur. \\
\hline $1 /$ chinook & Spring & $\begin{array}{l}\text { North Fork, } \\
\text { Nooksack River }\end{array}$ & Puget Sound & W & 1977 & $\mathrm{C}$ & A \\
\hline $2 /$ chinook & Spring & White River & Puget Sound & W & 1975 & A & A \\
\hline $3 /$ chinook & Spring & White River & Puget Sound & W & 1989 & A & A \\
\hline 4/chinook & Summer & $\begin{array}{l}\text { Stillaguamish } \\
\text { River }\end{array}$ & Puget Sound & ST & 1981 & $\mathrm{~A} / \mathrm{C}$ & $\mathrm{A} / \mathrm{C}$ \\
\hline $5 /$ chinook & Summer & Methow River & Columbia River & W & 1991 & B & B \\
\hline $6 /$ chinook & Spring & Chiwawa River & Columbia River & W & 1991 & B & A \\
\hline 7/chinook & Spring & Methow River & Columbia River & W & 1992 & B & A \\
\hline 8/chinook & Fall & Hanford Reach & Columbia River & W & 1973 & B & B \\
\hline 9/chinook & Fall & Snake River & Snake River & W & 1985 & B & A \\
\hline $10 /$ chinook & Spring & $\begin{array}{l}\text { East Fork, } \\
\quad \text { Salmon River }\end{array}$ & Snake River & I & 1991 & B & A \\
\hline $11 /$ chinook & Spring & Tucannon River & Snake River & W & 1986 & B & A \\
\hline $12 /$ chinook & Spring & Imnaha River & Snake River & $\mathrm{O}$ & 1983 & B & A \\
\hline $13 /$ chinook & Spring & $\begin{array}{l}\text { Upper Salmon } \\
\text { River }\end{array}$ & Snake River & I & 1986 & B & A \\
\hline 14/chinook & Summer & Pahsimeroi & Snake River & I & 1970 & B & A \\
\hline $15 /$ chinook & Summer & $\begin{array}{l}\text { South Fork, } \\
\quad \text { Salmon River }\end{array}$ & Snake River & I & 1981 & B & A \\
\hline $16 /$ chinook & Fall & Cowichan River & British Columbia & DFO & 1982 & A & A \\
\hline $17 /$ chum & Summer & $\begin{array}{l}\text { Big Quilcene } \\
\text { River }\end{array}$ & Puget Sound & FWS & 1993 & A & A \\
\hline $18 /$ chum & Summer & Salmon Creek & Puget Sound & WOS & 1993 & A & A \\
\hline $19 /$ chum & Fall & Stave River & British Columbia & DFO & 1983 & A & A \\
\hline $20 /$ pink & Fall & Quinsam River & British Columbia & DFO & 1980 & A & A \\
\hline $21 /$ sockeye & - & Wenatchee River & Columbia River & W & 1989 & B & B \\
\hline $22 /$ steelhead & Summer & Imnaha River & Snake River & $\mathrm{O}$ & 1983 & B & B \\
\hline
\end{tabular}

${ }^{1}$ Abbreviations for the lead agencies responsible for these programs are as follows: DFO=Department of Fisheries and Oceans, Canada; FWS = United States Fish and Wildlife Service; I = Idaho Department of Fish and Game; $\mathrm{O}=$ Oregon Department of Fish and Wildlife; ST $=$ Stillaguamish Tribe; W $=$ Washington Department of Fish and Wildlife; WOS =Wild Olympic Salmon. In most cases additional groups, such as tribal co-managers, are also involved in project planning and operation.

${ }^{2}$ Goals: $\mathrm{A}=$ conservation; $\mathrm{B}=$ mitigation or harvest augmentation; $\mathrm{C}=$ research or monitoring.

\subsection{Program Evaluation}

Using the data collected in the worksheets, we evaluated each program according to 12 specific criteria (Appendix 1) that are relevant to 5 basic objectives that can be used to characterize the success of a supplementation program (Table 2). Summarizing the data in this way allows a hierarchical evaluation of the performance of individual programs, as well as an overall assessment of 
Table 2. Basic supplementation objectives and how they were evaluated to estimate the success of Pacific salmon supplementation

Objective How objective was measured

(1) Collect broodstock

Collect a representative sample of the target population

Avoid collection of non-target populations

(2) Maintain higher survival (prespawning, egg-to-release, adult-to-adult) in the hatchery than in the wild

(3) Hatchery-produced fish and their progeny spawn and reproduce in the wild

(4) Increase abundance of natural spawners

(5) Population remains at higher abundance level after supplementation ceases

Directly, by comparing distributions; or indirectly, by evaluating collection methods

By using genetic and physical marks and evaluating collection methods

By calculating the geometric means over all years of data (We used literature values if survival data for the wild population were not available. If adult-to-adult return rates were not reported but release-to-adult return rates were, we used the release-to-adult rate, fecundity estimates [either reported or literature values], and reported egg-to-release survival rates to obtain an estimate of the adult-to-adult return rate.)

Method varied among programs

By comparing geometric mean abundance for 4 years prior to supplementation with mean abundance during most recent 4 years

By comparing abundance before and after supplementation and evaluating trend after supplementation

the performance of supplementation in general. This approach also allows a particular program to be evaluated in the context of specific goals for that program.

\section{RESULTS}

The majority of the 22 programs included in this study are for chinook salmon (Oncorhynchus tshawytscha) from the Columbia River, but 6 programs from Puget Sound and 3 from British Columbia are also included, as are programs for chum (Oncorhynchus keta), sockeye (Oncorhynchus nerka), and pink (Oncorhynchus gorbuscha) salmon and steelhead (anadromous rainbow trout, Oncorhynchus mykiss) (Table 1). Although we will continue to expand the geographic and species coverage of the supplementation database, we believe that the results presented here represent the majority of the supplementation programs in the Pacific Northwest that have been conducted for long enough to allow some evaluation of adult returns. All of the programs considered here have run for at least two salmon generations, and some have been in existence for over 20 years. Program performance with respect to the nested sets of objectives is summarized below. 


\subsection{Broodstock Collection}

The first step in a supplementation program is collection of broodstock. Although a few programs in the Pacific Northwest now focus on collection of juveniles for rearing to maturity in captivity, only programs that collected adults were considered here. To minimize founder effect in developing the hatchery broodstock, supplementation programs typically try to ensure that broodstock collection is as representative as possible of the target population. As discussed by Waples (1999), any process of sampling (unless the whole population is taken into captivity) will result in a hatchery broodstock that differs in some respects from the target population. We considered two criteria in evaluating the ability of programs to obtain representative samples of broodstock: run timing and age structure. For only about a third of the programs were we able to obtain adequate data to determine whether broodstock collection was representative. About as many others documented the collection methods well enough that a qualitative assessment could be made (Table 3A). Of the programs with direct or inferential information, the majority suggested that the run-time and/or age distributions were similar in the hatchery broodstock and the wild population. Failure to obtain a representative sample of broodstock (as occurred in some programs) often was the result of inability to collect fish over the entire spectrum

Table 3. Characterization of supplementation programs listed in Appendix 1 for six important measures of success. Data shown are numbers of programs falling into each category $(N=22$ programs total). A. Broodstock collection information. B. Survival in the hatchery environment. C. Adult-to-adult survival of hatchery-produced fish. D. Performance of hatchery-reared fish that spawn naturally. E. Population status before and after supplementation. F. Treatment/control response to supplementation. Dash $=$ zero

A.

\begin{tabular}{lccccc}
\hline Broodstock collection & Yes & (Yes) & No & (No) & No data \\
\hline Representative with respect to run timing? & 4 & 7 & 2 & 1 & 8 \\
Representative with respect to age structure? & 4 & 6 & 1 & 1 & 10 \\
Collected only from the target population? & 17 & - & 5 & - & - \\
\hline
\end{tabular}

${ }^{1}$ Direct data not available, but evaluation of broodstock collection methods suggests whether or not broodstock was representative.

B.

\begin{tabular}{lcc}
\hline Survival in hatchery & Prespawning $^{1}$ & Offspring, egg-to-release \\
\hline$>90 \%$ & 12 & 1 \\
$80-90 \%$ & 6 & 12 \\
$70-80 \%$ & - & 6 \\
$<70 \%$ & - & 2 \\
No data & 4 & 1 \\
\hline
\end{tabular}

\footnotetext{
${ }^{1}$ Survival of adults in captivity after collection from the wild.
} 
Table 3. Characterization of supplementation programs listed in Appendix 1 for six important measures of success. Data shown are numbers of programs falling into each category $(N=22$ programs total). A. Broodstock collection information. B. Survival in the hatchery environment. C. Adult-to-adult survival of hatchery-produced fish. D. Performance of hatchery-reared fish that spawn naturally. E. Population status before and after supplementation. F. Treatment/control response to supplementation. Dash $=$ zero — cont'd.

C.

\begin{tabular}{lcc}
\hline Ratio & In hatchery $^{1}$ & Hatchery:wild $^{2}$ \\
\hline$>5 \mathrm{x}$ & 5 & 6 \\
$2-5 \mathrm{x}$ & 5 & 6 \\
$1-2 \mathrm{x}$ & 2 & - \\
Equal & 1 & 3 \\
$<1 \mathrm{x}$ & 2 & - \\
No data & 7 & 7 \\
\hline
\end{tabular}

${ }^{1}$ Adult-to-adult replacement rate for broodstock spawned in the hatchery.

${ }^{2}$ Relative adult-to-adult replacement rate for hatchery fish compared to wild fish. Numbers include programs for which data are available only for the hatchery population and an estimate has been made of adult-to-adult survival in the wild.

D.

\begin{tabular}{lcc}
\hline Hatchery:wild ratio & Reproductive success & Offspring survival \\
\hline$>1 \mathrm{x}$ & - & - \\
About equal & 1 & 1 \\
$<1 \mathrm{x}$ & 2 & - \\
No data & 19 & 21 \\
\hline
\end{tabular}

E.

\begin{tabular}{lcc}
\hline Population status & Before $^{1}$ & After $^{2}$ \\
\hline Healthy & 1 & - \\
Depressed & 8 & - \\
At risk & 10 & - \\
Critical & 3 & 2 \\
\hline
\end{tabular}

1 "Before" status assessments represent judgments of those involved in the supplementation programs.

${ }^{2}$ Nineteen of 21 programs are still being supplemented and therefore do not allow an evaluation of "after supplementation" status.

F.

Treatment

\begin{tabular}{lcc}
\cline { 2 - 3 } Number of natural spawners & Supplemented & Control $^{2}$ \\
\hline Increased $>20 \%$ & 8 & 1 \\
Unchanged & 1 & 2 \\
Declined $>20 \%$ & 10 & 5 \\
No data & 3 & - \\
\hline
\end{tabular}

${ }^{1}$ Geometric means of most recent 4 years and 4 years immediately preceding collection of broodstock.

${ }^{2}$ Unsupplemented control populations were not available for most programs. 
of run timing - for example, because it was impossible to operate a collection weir (or because the weir became ineffective) at high stream-flow levels.

Another critical measure is the degree to which the program was able to avoid collection of fish from non-target populations. For 17 of the 22 programs, available data either provided evidence that the managers were effective in collecting only the target population or provided no evidence to indicate this was not the case. In the remaining five programs, however, the integrity of the broodstock was compromised by unintentional collection of individuals from other populations. Factors that led to this situation included placing collection facilities at locations downstream of areas that support multiple geographic or temporal populations, inability to screen out stray hatchery fish, and collecting mixtures of populations with different run timings.

\subsection{Survival in Captivity}

Most programs showed high survivals of cultured fish while they were held in captivity (Table 3B). Two-thirds of the programs for which data were available (12 of 18) had prespawning survival of the broodstock in excess of $90 \%$ (the rest had survivals over $80 \%$ ), and 19 of 21 programs with data available had egg-tosmolt survivals of offspring in excess of $70 \%$. Some programs had high in-culture survivals in most years but occasionally experienced much lower survivals. Other programs showed consistently high in-culture survivals in later years after experiencing difficulties in some early years. Factors contributing to the occasionally high in-culture mortality included disease outbreaks and unfavorable water temperatures (especially during holding of prespawning adults).

\subsection{Adult-to-Adult Survival}

Adult survival of program fish (i.e., broodstock and hatchery offspring) was evaluated from two perspectives (Table 3C). First, we computed the geometric mean adult-to-adult replacement rate for fish collected as broodstock - that is, the number of adults produced in the next generation for each broodstock adult taken from the wild. Surprisingly, we were unable to obtain data for this key performance measure for almost one-third of the programs. Of those with data, all but three showed a net replacement rate of greater than 1:1. In ten programs, the geometric mean replacement rate was in excess of 2.0 , which suggests the potential for rapidly increasing overall population size through artificial propagation.

Second, we compared adult-to-adult replacement rates for the hatchery broodstock to those experienced by the wild population. This allowed us to answer a key question for supplementation programs: whether taking fish into captivity produces more adults the next generation than would have been achieved by letting those same adults spawn naturally. In addition, this relative measure provides a potential means of demonstrating a supplementation benefit that might otherwise be overlooked: even if a program has an adult-to-adult 
replacement rate less than 1.0, it may still be providing at least a short-term conservation benefit (by slowing the population's rate of decline) if the replacement rate is even lower in the wild population. Again, for many programs we were not able to obtain sufficient data to make such an evaluation. In most programs for which data were available, the hatchery provided at least a twofold increase in the adult-to-adult return rate compared to the wild population.

\subsection{Performance of Hatchery Fish in the Wild}

Data are almost non-existent for the performance of hatchery-spawned fish after they return as adults (Table 3D). We did not find comprehensive data for any program on the reproductive success of hatchery-produced fish that spawn in natural habitat. For three programs we had partial data relevant to this determination; of these, two suggested a reduction compared to the wild population (hatchery fish that returned to the rivers to spawn were younger, smaller, or had lower fecundity) and one showed no difference (naturally spawning hatchery and wild fish had similar fecundity; see Appendix 1). We found only one program (Tucannon River spring chinook salmon) with even partial data on the survival or performance of the progeny of naturally spawning hatchery fish. For this program, the relationship between the number of redds and the number of progeny did not substantially change as the fraction of hatchery spawners increased, suggesting similar productivity of hatchery and wild fish (J. Bumgarner, Washington Department of Fish and Wildlife, personal communication). In this same program, data for the early 1990s showed that, compared to natural adults, returning hatchery fish were younger, were smaller for the same age, and had lower fecundity for the same size (Bugert et al., 1992). These conflicting results emphasize the need for more rigorous evaluation of the performance of hatchery fish in the wild.

Even if naturally spawning hatchery fish have reduced success in the wild, a supplementation program may still provide a net short-term demographic benefit if the reduction in productivity is more than offset by the substantial survival benefit during the juvenile phase that typically occurs in a hatchery. We found no programs with sufficient data to make a direct, short-term evaluation of this type. A rigorous evaluation of long-term demographic benefits of supplementation also would have to include an assessment of the longterm fitness consequences of reduced reproductive success by hatchery fish and an evaluation of the rate at which fitness could be naturally restored after supplementation ended. Again, research that would address these questions has not been conducted for any of the programs we evaluated.

\subsection{Population Response}

An ideal long-term study of the effects of supplementation would include a number of supplemented populations and a number of comparable, control 
populations that were not supplemented. The ideal study would also include information from before, during, and after supplementation in the treatment and control streams. If supplemented populations were more robust than controls, and if this difference persisted even after supplementation was terminated, it would be a convincing demonstration of the long-term effectiveness of supplementation. Because we found no studies that satisfied these ideal conditions, we considered various types of analyses that might provide at least partial insight into the effectiveness of supplementation. (Note: The experimental design for some current supplementation programs [e.g., Bowles and Leitzinger, 1991] includes paired control and treatment streams, but the studies are ongoing and a complete analysis of their effectiveness is not possible at this time. Preliminary data for these ongoing programs have been incorporated into this report.)

A comparison of the status of populations before and after treatment is largely uninformative with respect to salmon supplementation. Only two programs we evaluated can be considered completed (Table 3E), but neither was terminated because the population recovered. One program (White River spring chinook) was terminated but a different type of supplementation program was started soon thereafter in the same basin, and another (East Fork Salmon River) was suspended because too few fish returned to support broodstock collection. Therefore, it is impossible at this point to collect any "after treatment" data for most supplementation programs. (After this review was completed we received a report [Ames and Adicks, 2003] on supplementation programs for summer chum salmon in two areas of South Puget Sound; the programs were conducted from 1976 to 1991 . Using the same criteria applied elsewhere in this report, recent run sizes in Case Inlet and Hammersley Inlet streams were approximately 1.5-2.5 times as large as presupplementation values. This report, therefore, describes an example in which population size was higher after supplementation ended than it was before. However, the report does not contain comparable information for unsupplemented control streams. Recent abundance of chum salmon in other areas of Puget Sound has also been quite high, which complicates the interpretation of these results.)

Another approach is to compare the population abundance before supplementation with the current abundance. If a goal of supplementation is to help promote a viable population after the program ceases, it should at a minimum be able to increase population abundance during supplementation. About half (10 of 22) of the supplemented populations declined in size after supplementation began, while nine populations increased in size or were stable (Table 3F; data are not available for three populations). This result by itself is difficult to interpret because external factors unrelated to supplementation undoubtedly affected the abundance of many of these populations. For example, most populations in this study were considered depressed or at some risk of extinction before supplementation began (Table 3E), and long-term recovery is not likely even with supplementation unless the factors that contributed to the initial decline are addressed. 
In a few of the cases we examined, significant improvements in survival were achieved (e.g., by harvest rate reductions) concurrently with initiation of the supplementation program. In these cases, it can be difficult to determine the actual cause of a population's increase in abundance.

Some insight into the effects of these external factors might be gained from evaluating the behavior of unsupplemented control populations, but comparable control populations were available for only about a third (8 of 22) of the programs. Overall, the response of the supplemented populations was slightly better than the control populations. Paired supplemented and control populations had similar abundance trends in five of the eight cases; the supplemented population outperformed the control population in two cases, while the control population performed better in another program. Considering all programs with available data, a much higher percentage of the supplemented populations increased ( 8 of 19 supplemented populations increased versus 1 of 8 control populations). However, a majority of the supplemented populations that increased did not have paired control populations, thus limiting the conclusions that can be drawn from these data.

\section{DISCUSSION AND CONCLUSIONS}

This review is brief and preliminary in nature, and in it we do not attempt a comprehensive evaluation of salmon supplementation. A number of important considerations are outside the scope of this study. For example, we did not do the following:

1. provide detailed discussion of individual programs or detailed analysis of the factors believed to be responsible for the degree of success in attaining each objective;

2. analyze information on a number of important population attributes that might be affected by supplementation, such as genetic and life-history traits and spawning distribution;

3. evaluate program performance as a function of differences in culture techniques (e.g., mating, rearing, and release strategies);

4. evaluate program performance with respect to specific goals of the program. Each of these factors is important and could form the basis of one or more subsequent reports.

Instead, in this paper we have focused on meta-analysis of empirical data for several performance criteria that should be associated with successful supplementation programs. Results summarized above and in Tables 3 and 4 make it clear that there is a major dichotomy in the degree to which supplementation programs have achieved their objectives. In terms of the ability to boost overall numbers of fish, many of the programs have been relatively successful. Examples of this type of success include high survivals of both broodstock and offspring in captivity and increases in the number of returning hatchery adults compared to the wild population. Many supplementation programs, therefore, 
Table 4. Summary of program performance with respect to hierarchical objectives. Data shown are numbers of programs listed in Appendix 1 and falling into each category. Unc. =uncertain; $\mathrm{H}=$ hatchery; $\mathrm{W}=$ wild; $N_{\mathrm{t}}=$ number at completion of study; $N_{\mathrm{o}}=$ number at initiation of study

\begin{tabular}{|c|c|c|c|c|}
\hline \multirow[b]{2}{*}{ Objective } & \multirow[b]{2}{*}{ Criterion } & \multicolumn{3}{|c|}{ Was objective met? $^{1}$} \\
\hline & & Yes & No & Uncertain \\
\hline \multicolumn{5}{|l|}{ Broodstock collection } \\
\hline \multicolumn{5}{|l|}{ Representativeness } \\
\hline Run timing & Similar to wild & 11 & 3 & 8 \\
\hline Age & Similar to wild & 10 & 2 & 10 \\
\hline Integrity & $<5 \%$ non-native & 17 & 5 & - \\
\hline \multicolumn{5}{|l|}{ Survival in culture } \\
\hline Prespawning survival & $>90 \%$ & 12 & 6 & 4 \\
\hline Egg-to-smolt survival & $>70 \%$ & 19 & 2 & 1 \\
\hline Adult-to-adult survival & $>2.0$ in hatchery or $>2.0 \mathrm{H}: \mathrm{W}$ ratio & 12 & 4 & 6 \\
\hline Reproductive success in the wild & Comparable to wild fish & 1 & 2 & 19 \\
\hline Population increase & $N_{\mathrm{t}}>120 \% N_{0}$ & 8 & 11 & 3 \\
\hline Viability of natural population & $\begin{array}{l}\text { Population stable at higher level } \\
\text { after supplementation }\end{array}$ & - & 2 & 20 \\
\hline
\end{tabular}

${ }^{1}$ Data shown are numbers of programs falling into each category.

have achieved a measure of success in the aspects of fish culture traditionally associated with salmon hatcheries.

Producing fish, however, is only the first step in a successful supplementation program; it is also necessary that fish produced by the program and their progeny contribute to productivity of the natural population in future generations. From this perspective, the success of salmon supplementation cannot be evaluated because there are essentially no data (Table 4 and Appendix 1). To date, only a few studies have evaluated the performance of hatchery fish and their progeny in the natural environment. Theoretical considerations lead to the conclusion that cultured fish should have reduced fitness in the wild, and the experimental data that are available (e.g., Reisenbichler and McIntyre, 1977; Fleming and Gross, 1993; Reisenbichler and Rubin, 1999; Hindar and Fleming, 2007) support this premise. However, some of these experimental studies confound the effects of domestication with the effects of stock transfers, making it difficult to make predictions about supplementation programs using locally derived broodstock (as considered in this report). The key question to resolve in evaluating long-term benefits of salmon supplementation is whether the demographic boost provided by the hatchery more than offsets reduced fitness in the wild of hatchery-produced fish and their progeny. This can best be evaluated by empirical studies in the natural environment, which have not yet been conducted rigorously for any supplementation program for which we have information.

Two major conclusions emerge from this preliminary evaluation of salmon supplementation. First, the premise that supplementation can be used to provide 
a net long-term benefit to natural populations remains an untested hypothesis. We, like Miller et al. (1990), have not found any examples in which salmon supplementation has been used to help a natural population become selfsustaining. This does not mean that supplementation cannot provide this type of benefit; most supplementation programs have not been terminated yet, which makes it difficult to evaluate sustainability of the natural population. Furthermore, supplementation alone cannot be expected to result in a viable population if the factors responsible for the original decline have not been remedied. However, the fact that one of the ultimate goals of salmon supplementation has never been empirically demonstrated should serve as a cautionary note to those considering initiating new programs or continuing existing ones.

Second, results presented here make it clear that the biggest gap in our knowledge about supplementation relates to the performance of hatcheryproduced fish and their progeny in the natural environment. More research is critically needed in this area. Ideally, such evaluations should be conducted over a number of generations to permit distinguishing between ecological and genetic effects of fish culture and to evaluate the effectiveness of natural selection to restore fitness in a natural population of mixed hatchery-wild ancestry. Gathering this type of information is challenging but feasible using highly polymorphic molecular genetic markers that allow fine-scale resolution of reproductive success in the wild. Parallel studies designed to identify the ecological, behavioral, and physiological factors responsible for fitness of hatchery fish in nature could suggest ways to make supplementation more successful in the long term.

These considerations also suggest some basic recommendations regarding supplementation:

1. Because of the largely unproven track record with respect to key objectives, salmon supplementation should be considered experimental. The appropriate use should be determined only after a comprehensive risk-benefit analysis that considers details specific to the target population and the proposed program as well as more general issues associated with supplementation.

2. When supplementation is used, comparable unsupplemented populations should be included as controls, and performance of both treatment and control populations should be measured with a rigorous monitoring and evaluation program. Doing this would ensure that valuable research and adaptive management information is compiled during the course of these "experiments."

\section{ACKNOWLEDGMENTS}

We are indebted to those who graciously provided us unpublished data for use in this analysis, including L. Brown, J. Bumgarner, P. Castle, C. Cross, J. Foster, P. Hassemer, T. Johnson, R. Johnson, T. Kane, K. Killebrew, 
S. Lehmann, G. Mendel, and J. Walters. A Steering Committee composed of regional fishery biologists familiar with salmon supplementation (A. Appleby, R. Carmichael, J. Colt, E. Crateau, K. Currens, P. Hassemer, G. James, D. Johnson, K. Killibrew, and A. Talbot) provided guidance for this project and facilitated data collection. J. Ames, B. Berejikian, J. Bumgarner, I. Fleming, J. Krakker, and an anonymous reviewer provided useful comments on an earlier draft of this manuscript.

\section{REFERENCES}

Ames, J., and K. Adicks. 2003. Chum Salmon Supplementation: Bane or Boon? Final Report. Washington Department of Fish and Wildlife, Olympia, Washington, USA. 20 pp.

Bowles, E., and E. Leitzinger, 1991. Salmon Supplementation Studies in Idaho Rivers (Idaho Supplementation Studies): Experimental Design. Report to the U.S. Department of Energy, Bonneville Power Administration, Division of Fish and Wildlife, Portland, Oregon for Project Number 89-098. Idaho Department of Fish and Game, Boise, Idaho, USA. 167 pp.

Bugert, R., K. Petersen, G. Mendel, L. Ross, D. Milks, J. Dedloff, and M. Alexandersdottir. 1992. Lower Snake River Compensation Plan, Tucannon River Spring Chinook Salmon Hatchery Evaluation Plan. Annual Report for 1991 to U.S. Fish and Wildlife Service, Boise, Idaho. Washington Department of Fish and Wildlife, Olympia, Washington, USA.

Busack, C.A., and K.P. Currens. 1995. Genetic risks and hazards in hatchery operations: fundamental concepts and issues. In: H.L. Schramm, Jr., and R.G. Piper (eds.), Uses and Effects of Cultured Fishes in Aquatic Ecosystems. American Fisheries Society Symposium 15. American Fisheries Society, Bethesda, Maryland, USA. Pp. 71-80.

Fleming, I.A., and M.R. Gross. 1993. Breeding success of hatchery and wild coho salmon (Oncorhynchus kisutch) in competition. Ecological Applications 3: 230-245.

Hindar, K., and I.A. Fleming. 2007. Behavioral and genetic interactions between escaped farm and wild Atlantic salmon. In: T.M. Bert (ed.), Ecological and Genetic Implications of Aquaculture Activities. Springer Publications, New York City, New York, USA. Chapter 7.

Lichatowich, J. 1999. Salmon without Rivers: A History of the Pacific Salmon Crisis. Island Press, Covelo, California, USA. 317 pp.

Miller, W.H., T.C. Coley, H.L. Burge, and T.T. Kisanuki. 1990. Analysis of Salmon and Steelhead Supplementation. Part I: Emphasis on Unpublished Reports and Present Programs. Technical Report, Project 88-100 to the U.S. Department of Energy, Division of Fish and Wildlife. Bonneville Power Administration, Portland, Oregon, USA. 46 pp. + appendices.

National Research Council. 1996. Upstream: Salmon and Society in the Pacific Northwest. National Academy Press, Washington, D.C., USA. 452 pp.

Peterman, R.M. 1981. Form of random variation in salmon smolt-to-adult relations and its influence on production estimates. Canadian Journal of Fisheries and Aquatic Sciences 38: 1113-1119.

Reisenbichler, R.R., and J.D. McIntyre. 1977. Genetic differences in growth and survival of juvenile hatchery and wild steelhead trout, Salmo gairdneri. Journal of the Fisheries Research Board of Canada 34: 123-128.

Reisenbichler, R. R., and S. P. Rubin. 1999. Genetic changes from artificial propagation of Pacific salmon affect the productivity and viability of supplemented populations. ICES Journal of Marine Science 56: 459-466.

Waples, R.S. 1995. Evolutionarily significant units and the conservation of biological diversity under the Endangered Species Act. In: J.L. Nielsen (ed.), Evolution and the Aquatic Ecosystem: Defining Unique Units in Population Conservation. American Fisheries Society Symposium 17. American Fisheries Society, Bethesda, Maryland, USA. Pp. 8-27.

Waples, R.S. 1999. Dispelling some myths about hatcheries. Fisheries 24(2): 12-21. 


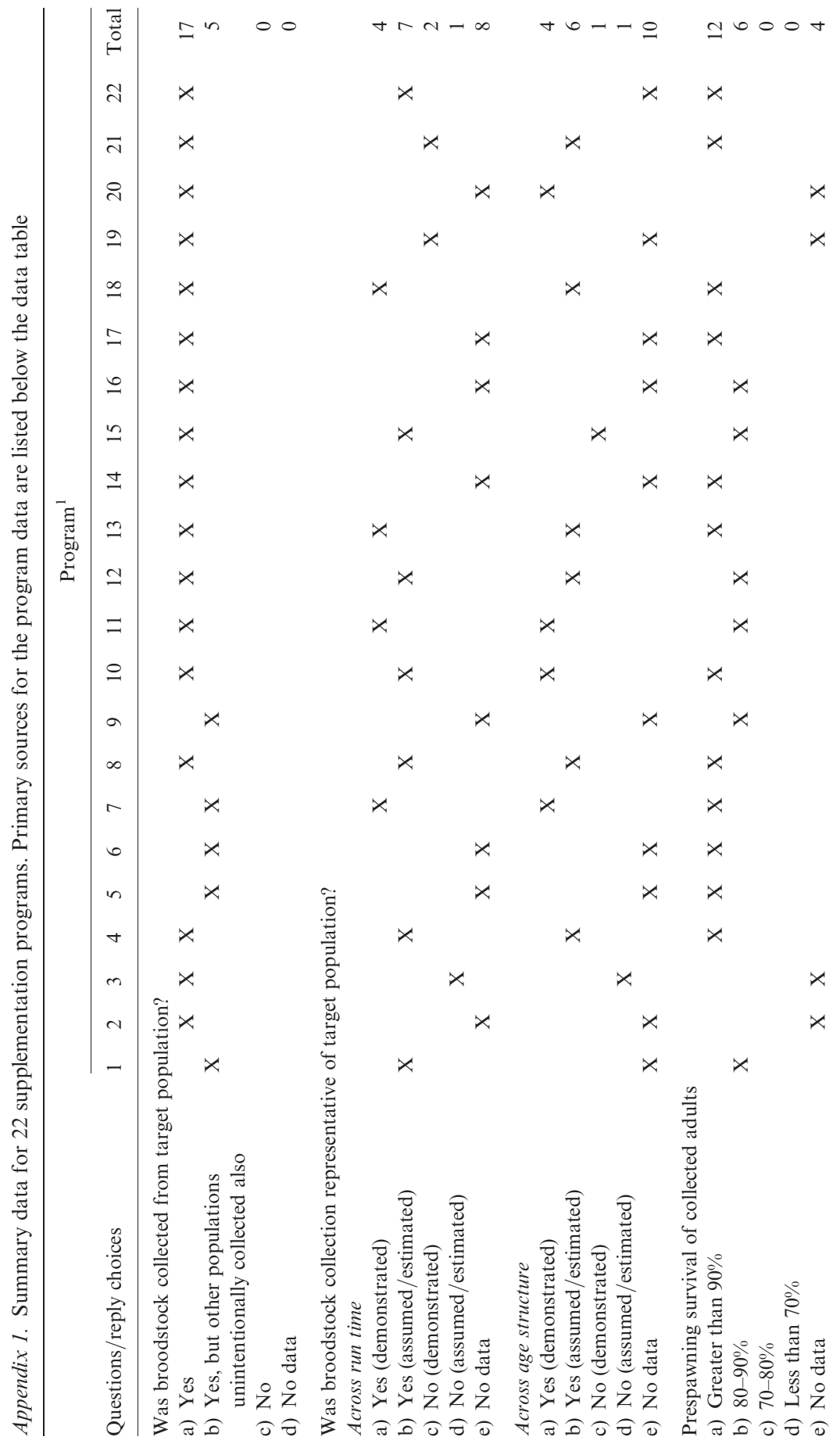




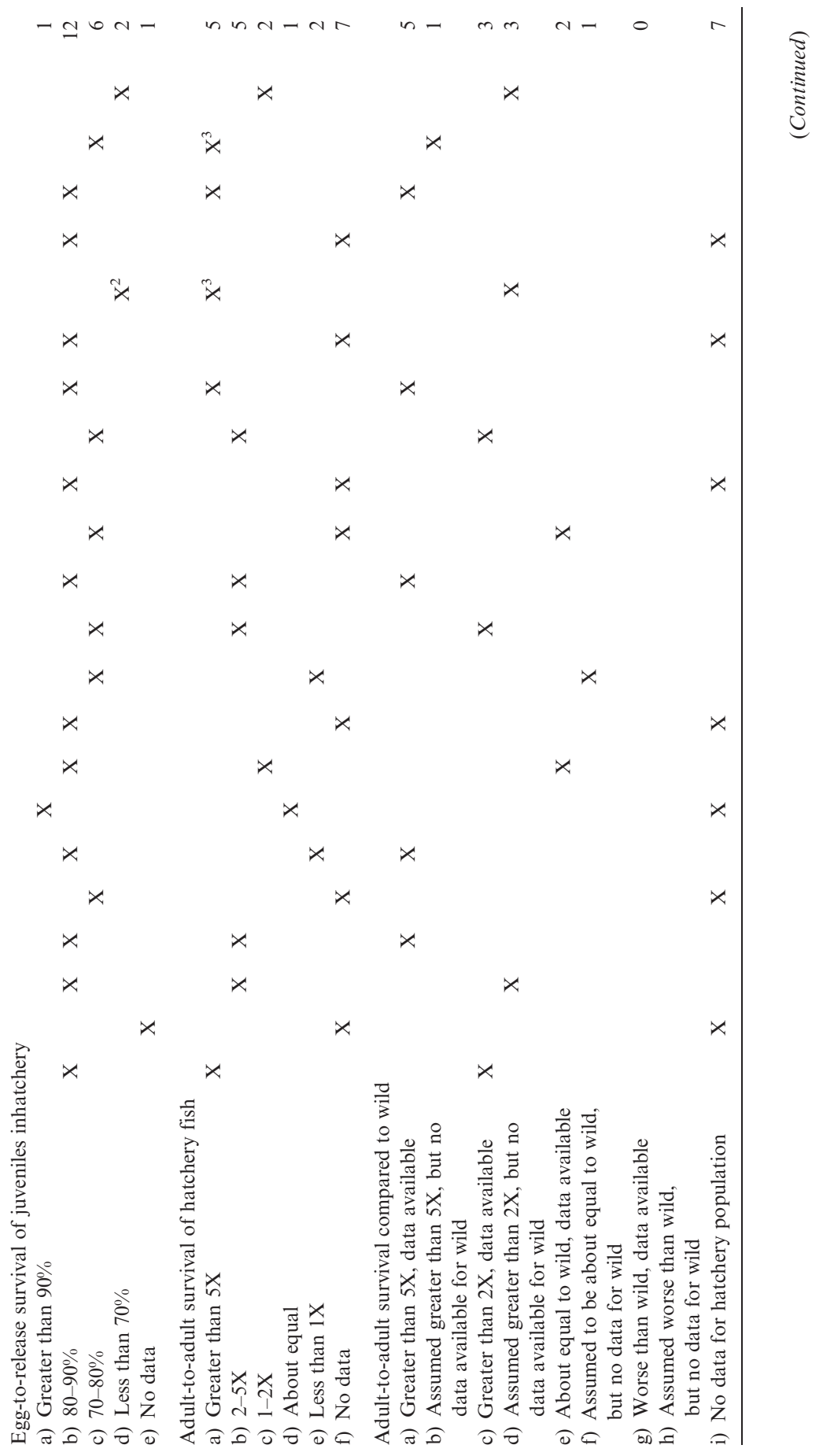




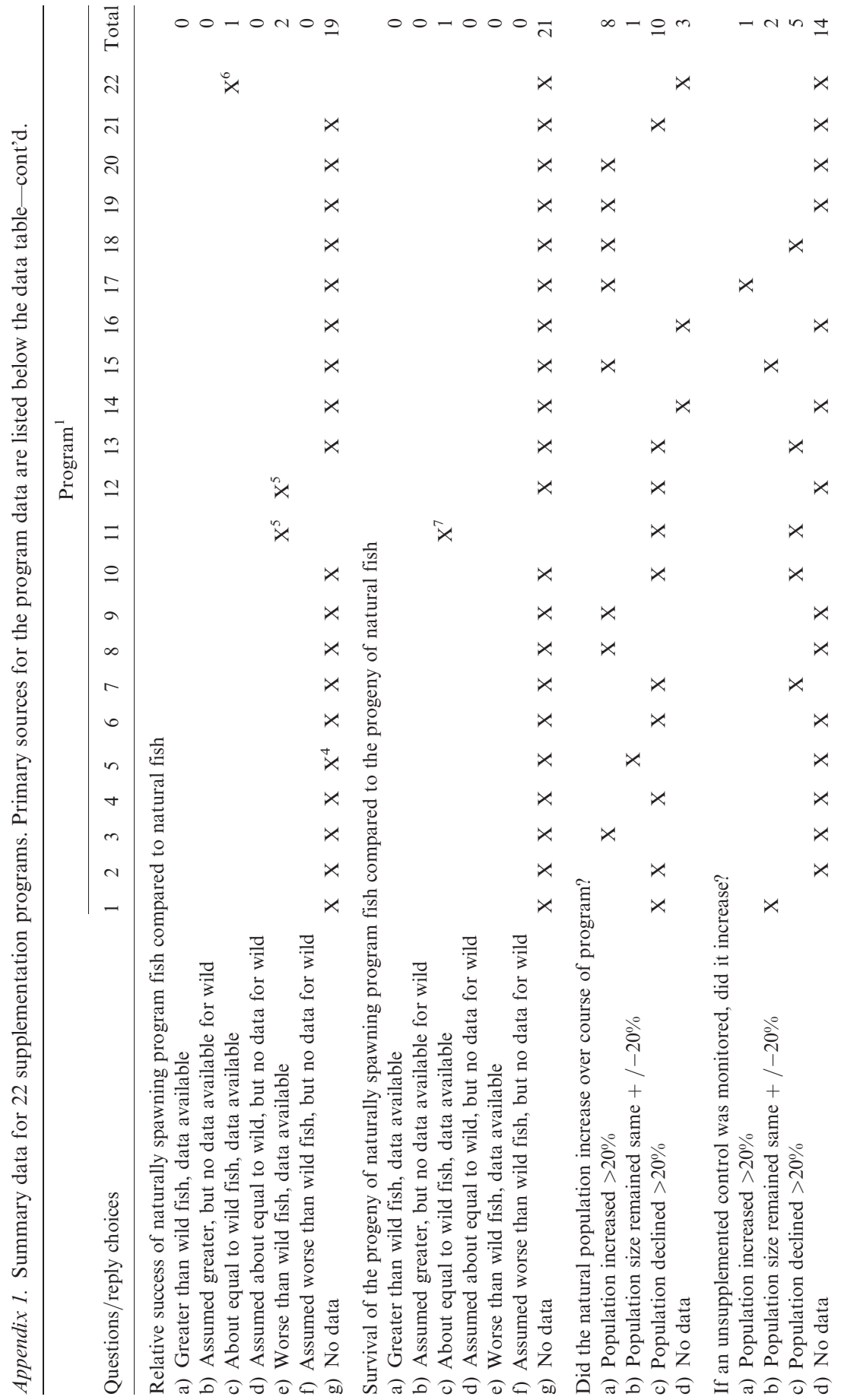




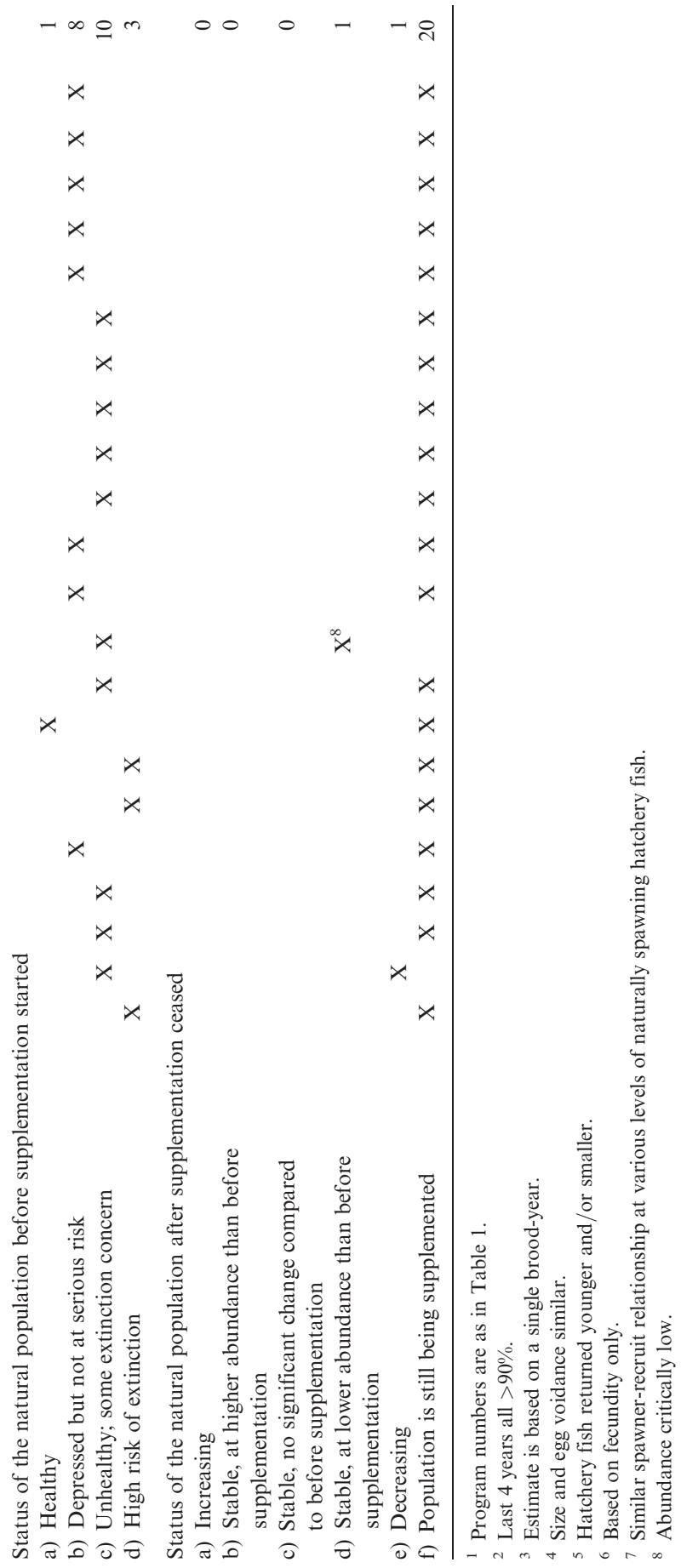


Primary sources of information for these programs were as follows (program numbers are as above and in Table 1):

1 Fuss, H.J., and C. Ashbrook. 1995. Hatchery Operation Plans and Performance Summaries, Volume I, Number 2, Puget Sound. Washington Department of Fish and Wildlife, Hatcheries Program, Assessment and Development Division, Olympia, Washington, USA.

2, 3 Washington Department of Fish and Wildlife, Puyallup Indian Tribe, and Muckleshoot Indian Tribe. 1998. Recovery Plan for White River Spring Chinook Salmon. Update. Washington Department of Fish and Wildlife, Olympia, Washington, USA. 81 pp.

4 Drotts, J. 2000. Hatchery and Genetic Management Plan: US/Canada Chinook Indicator Stock Study and Restoration Program. Stilliguamish Tribe, Arlington, Washington, USA. $200 \mathrm{pp}$.

5 Miller, M.D., and T.W. Hillman. 1998. Summer/Fall Chinook Salmon Spawning Ground Survey in the Methow and Okanogan River Basins 1997. BioAnalysts Incorporated, Boise, Idaho, USA. 62 pp. + appendices.

6 Peck, L. 1998. Application for a Permit to Enhance the Propagation or Survival of Endangered or Threatened Species under the Endangered Species Act of 1973. Washington Department of Fish and Wildlife, Olympia, Washington, USA.

7 Bartlett, H. 1998. 1996, Methow Spring Chinook Summary Report. Washington Department of Fish and Wildlife, Omak, Washington, USA. 46 pp.

8 Dauble, D.D., and D.G. Watson. 1997. Status of fall chinook populations in the midColumbia River. North American Journal of Fisheries Management 17(2): 283-300.

9 Mendel, G., J. Bumgarner, D. Milks, L. Ross, and J. Dedloff. 1996. Lyons Ferry Hatchery Evaluation: Fall Chinook, 1995 Annual Report. Washington Department of Fish and Wildlife, Assessment and Development Division of the Hatcheries Program, Olympia, Washington, USA. 63 pp.

10, 13, 14, 15 Bowles and Leitzinger (1991; cited in References section).

10, 13 Cannamela, D.A., and J.V. Younk. 1998. 1997 Annual Report to National Marine Fisheries Service for Permits \#919 and \#920 for the Chinook Salmon Program at East Fork Salmon River and Sawtooth Fish Hatchery. Idaho Department of Fish and Game, Boise, Idaho, USA. $10 \mathrm{pp}$.

11 Bumgarner, J., G. Mendel, D. Milks, L. Ross, J. Dedloff, and M. Varney. 1997. Tucannon River Spring Chinook Salmon Hatchery Evaluation Program. Washington Department of Fish and Wildlife, Hatcheries Program/Assessment and Development Division, Olympia, Washington, USA. 43 pp.

12 Carmichael, R.W., and R.T. Messmer. 1995. Status of Supplementing Chinook Salmon Natural Production in the Imnaha River Basin. In: H.L. Schramm, Jr., and R.G. Piper (eds.), Uses and Effects of Cultured Fishes in Aquatic Ecosystems. American Fisheries Society Symposium 15. American Fisheries Society, Bethesda, Maryland, USA. Pp. 284-291.

16, 20 Greg Bonnell, Department of Fisheries \& Oceans, Vancouver, British Columbia, Canada, personal communication.

17, 18 Washington Department of Fish and Wildlife and Point No Point Treaty Tribes. 2000. Summer Chum Salmon Conservation Initiative: An Implementation Plan to Recovery Summer Chum Salmon in the Hood Canal and Strait of Juan de Fuca Region. Washington Department of Fish and Wildlife. Electronic publication. Website: http://wdfw.wa.gov/fish/chum/ sumchum.pdf

19 Don Bailey, Department of Fisheries \& Oceans, Vancouver, British Columbia, Canada, personal communication.

21 Petersen, K., A. Murdoch, M. Tonseth, T. Miller, and C. Snow. 1999. 1995 Brood Sockeye and Chinook Salmon Reared and Released at Rock Island Fish Hatchery Complex Facilities. Washington Department of Fish and Wildlife, Olympia, Washington, USA. 47 pp. 
22 Carmichael, R.W., T.A. Whitesel, and B.C. Jonasson. 1995. Evaluation of the Success of Supplementing Imnaha River Steelhead with Hatchery Reared Smolts: Phase I, Completion Report. Bonneville Power Administration, Public Information Center - CKPS-1, Portland, Oregon, USA. $161 \mathrm{pp}$.

Whitesel, T.A., R.W. Carmichael, M.W. Flesher, and D.L. Eddy. 1998. Summer Steelhead in the Imnaha River Basin, Oregon. In: D. Herrig (ed.), Lower Snake Compensation Plan Status Review Symposium. U.S. Fish and Wildlife Service, Boise, Idaho, USA. Pp. 32-42.

All projects: Streamnet Database. 1999. Streamnet On-line Data Query. Electronic publication. Website: http://www.streamnet.org

Pacific States Marine Fishery Council. 1999. Regional Mark Information System On-line Data Query. Electronic publication. Website: http://www.psmfc.org 